\title{
Research on U.S Economic Growth and Transformation in Recent Century: from the Perspective of Collaborative Theory
}

\author{
Jianhua LIU \\ School of Management Engineering, Zhengzhou University, Zhengzhou 450000, China \\ Zhaohua JIANG \& Shuang LIU \\ School of Public Administration and Law, Dalian University of Technology, Dalian 116023, China
}

\begin{abstract}
This paper briefly reviews the researches on U.S. economic growth, and from the perspective of Collaborative Theory, it establishes a growth model for American economy in recent 100 years from 1900 to 2008 , and then it calculates the contribution rate of science and technology, human capital, fixed capital stock, investment in fixed assets, the system and the externality of economic environment to American economic growth. At last, it analyzes and explains the calculation results.
\end{abstract}

KEYWORD: Collabarative Theory; U.S. economic growth; contribution rate calculation; innovative country

\section{RESEARCHES RELATED TO THE ANALYSIS OF ECONOMIC GROWTH FACTORS}

\subsection{Jones' research}

The first generation of R\&D Endogenous Economic Growth Model derived from the Endogenous Technological Transition Model put forward by Romer, who claimed that the increase of intermediate input could boost the productivity of R\&D departments. Jones [1] (1995) studied the effect of $R \& D$ on productivity growth in OECD countries after World War II, but found no substantive effect despite their R\&D input were sharply increased. Therefore, he constructed an endogenous growth model for $\mathrm{R} \& \mathrm{D}$. This model reserved the two-sector model framework of symbiosis theory, which included final output sectors and knowledge production sectors, thus it retained the substitutive characteristic of knowledge that it is diffused cross time. While the model abandoned the presumed condition that endogenous cumulative factors have constant return to scale, thereby it reached the conclusion that there was no scale effect. This presumption implied that the contribution of population or knowledge stock to their own accumulation is far less than what is assumed by $R \& D$ endogenous growth model. [2]

\subsection{Jorgenson's research}

Another influential research was carried out by Dale Jorgenson, an economics professor from University of California, Berkeley. He researched the economic growth of Japan and America from 1960 to 1979, and separated their output growth into three sources, that is, the contribution of capital input, the contribution of labor input, and the technical progress rate. Through calculation, Jorgenson drew the conclusion that in the economic growth of the two countries, the capital input had played a decisive role, while the labor input had made significant contributions. [3] Through modeling the labor supply and demand of US in the next 25 years, Jorgenson, Gertler et al (2008) [4] arrived at the following conclusion: despite the scheduled arrival of the aging problem, the appropriate population increase still had provided sufficient supply for the labor market in the 21 st century. The improvement of the labor force is due to the recognition and emphasis on education, this pattern will last for a certain period of time, but it bound to disappear eventually. The year-to-year variation of economic activities is mainly the result of the capital accumulation; however, for a long period to come, the driving forth of economic growth will transfer to the labor force and technology.

\subsection{BLS' research}

In May 2001, US Bureau of Labor Statistics (BLS) published a research report Multifactor Productivity, which analyzed the factors of US labor productivity during more than 50 years from 1948 to 1999 , and then put forward the concept of multifactor productivity.

According to the report, the multifactor productivity resulted from the interactions of multiple factors, including $\mathrm{R} \& \mathrm{D}$, new technique, scale economy, organization and management technology and etc., and actually it was the technical progress in a general sense. The significance of this report is that it directly combined labor productivity and scientific-technical progress, and it analyzed the latter in diverse aspects, which had greatly carried forward researches on US productivity. 
Previous studies, such as the Solow Residual method and so forth, simply defined scientific-technical progress as: gross output - (labor force + capital).

\section{THE ENDOGENOUS THEORY AND METHOD OF ECONOMIC GROWTH}

\subsection{The theoretical basis}

To establish a universal economic growth model including scientific-technical progress, institutional innovation and other factors, we should start from certain basic principles of economics, this paper studies on economic growth on the basis of the distribution principle of GDP. From the perspective of distribution principle, GDP can be divided into labor remuneration (the broad sense of which includes wage, social security, relevant tax and etc.), capital gain (the broad sense of which includes depreciation, investors' profit, interest, relevant tax and etc.), symbiosis benefit, and so forth. The "symbiosis benefit" here is similar to the "accumulation fund" in joint-stock company's account, it is the "third item" independent of labor remuneration and capital gain, and the source of improving the innovation ability (to expanded reproduction and improve production capacity of new products), for it stems from the interaction and symbiosis of science and technology, investment in fixed assets, and human capital, thus the new growth theory can also be called as "symbiosis theory", and this is the starting point of the paper, which can be presented as

GDP $=$ labor remuneration + capital fund

$$
+ \text { symbiosis benefit }+\ldots
$$

Then, turn (1) to a quantitative form (and other quantitative forms):

$$
Y=a L^{\alpha} H^{\beta} S^{\gamma} D^{\delta}+b K+c_{1} H D / K+c_{2} S H / K+u
$$

In Formula (2), $Y$ stands for GDP, $L$ for labor forth, $H$ for human capital, and $S$ for science and technology input (in actual computation, it uses the data of last three period [last three years] to represents the hysteresis effect of science and technology on economic growth), $\mathrm{D}$ stands for investment in fixed assets, $\mathrm{K}$ for fixed capital stock (in actual computation, it uses the data of last period [last year]); $\alpha, \beta, \gamma, \delta, a, b, c_{1}$, $c_{2}$ and $u$ are parameters, they are decided by the externality of system and environment; in Formula (2), $a L^{\alpha} H^{\beta} S^{\gamma} D^{\delta}$ represents labor remuneration, $b K$ represents the earnings of fixed capital stock; $c_{1} H D / K+c_{2} S H / K$ represents symbiosis benefit, and $u$ represents the item of "..." in Formula (1).

$$
\mathrm{B}=a L^{\alpha} H^{\beta} S^{\gamma} D^{\delta}
$$

It includes the effect of labor force (L) and knowledge. The effect of knowledge consists of three parts: (1) the function of materialized knowledge, which is endogenous of investment in fixed assets; (2) the function of new knowledge brought by scientifictechnical progress $S$; (3) the function of human capital $\mathrm{H}$, which can be measured by education years and professional staff number.

\subsection{Earnings of fixed capital stock}

$$
\text { Earnings of fixed capital stock }=b K
$$

$K$ is the fixed capital stock of last period (last year), $b$ is the earning coefficient of fixed capital stock.

\subsection{Factorization of economic growth rate}

According to Formula (2), by solving total differential, we can construct the economic growth model, and confirm the relationship between GDP and labor force, human capital, science and technology input, fixed capital stock, investment in fixed assets, institutional factors and the externality of economic environment, thus to organically combine the reasonable factors of New Growth Theory and Neo-institutional economics.

Starting from Model (2), the following decomposition model of economic growth rate can be derived:

$$
\begin{aligned}
y= & \frac{b K-c_{1} H D / K-c_{2} S H / K}{Y} k \\
& +\frac{c_{1} H D / K+a \delta L^{\alpha} H^{\beta} S^{\gamma} D^{\delta}}{Y} d \\
& +\frac{c_{2} S H / K+a \gamma L^{\alpha} H^{\beta} S^{\gamma} D^{\delta}}{Y} s \\
& +\frac{c_{1} H D / K+c_{2} S H / K+a \beta L^{\alpha} H^{\beta} S^{\gamma} D^{\delta}}{Y} h \\
& +\frac{a \alpha L^{\alpha} H^{\beta} S^{\gamma} D^{\delta}}{Y} l+i+q
\end{aligned}
$$

In Formula (5), y , k , d , s , h and 1 are respectively the change rate of $Y$ (GDP), $K$ (fixed capital stock), $D$ (investment in fixed assets), $S$ (science and technique input), $H$ (human capital) and $L$ (labor force); $i$ and $q$ are respectively the effect of institutional innovation and that of the externality of economic environment on economic growth.

Through Formula (5), the contribution rate of different factors to economic growth can be easily calculated.

\subsection{Labor remuneration function}

Labor remuneration function can be written as: 
3 THE MEASUREMENT OF US ECONOMIC GROWTH IN RECENT CENTURY

\subsection{Economic growth model of America}

Firstly, establish the logarithmic model of labor remuneration, which is $\log \mathrm{B}$, and then establish the model; thus the economic growth accounting model of America built by the paper is as follows:

$$
\begin{aligned}
Y= & 1.016319(H L)^{0.48} *(S D / L)^{0.001434 t-0.000000045 t^{3}} \\
& +0.12 K+0.07 S D H / K \\
& +0.00696 S D H / K+11.72
\end{aligned}
$$

In Formula (6), $\mathrm{t}$ represents time, the year $1900=1$, the year $1978=79 \ldots$ the year $2008=109$. $Y$ is GDP, $K$ is the fixed capital stock, $D$ is the investment in fixed assets, $S$ is science and technique input, $H$ is human capital, $L$ is the labor force.

Through calculating and analyzing the data between 1990 and 2008 through econometric approach, the

\begin{tabular}{|c|c|c|c|c|c|}
\hline & $1900-1929$ & $1930-1947$ & $1948-1981$ & $1982-2000$ & 2001-2008 \\
\hline Economic growth rate & 3.1 & 3.7 & 3.4 & 3.3 & 2.2 \\
\hline Contribution rate of the increase of fixed capital stock $\%$ & 55.7 & 31.7 & 31.4 & 20.6 & 27.6 \\
\hline Contribution rate of the increase of Investment in fixed as sets $\%$ & 1.4 & 4.4 & 10.5 & 19.3 & 2.2 \\
\hline Contribution rate of scientific-technical progress $\%$ & 2.6 & 12.8 & 17.4 & 16.3 & 29.6 \\
\hline Contribution rate of the increase of human capital $\%$ & 20 & 17.5 & 18.7 & 21.1 & 16.9 \\
\hline Contribution rate of the increase of labor force $\%$ & 12.9 & 9.4 & 11.7 & 9.7 & 6.1 \\
\hline Contribution rate of institutional innovation $\%$ & -1 & 21.7 & 3.1 & 16.7 & 4.5 \\
\hline Influence rate of the externality of economic environment $\%$ & 8.4 & 2.5 & 7.2 & -3.7 & 13.1 \\
\hline
\end{tabular}
result obtained is as follows:

Chart 1 the economic growth accounting result obtained by this paper (\%)

\subsection{Measurement of the contribution rate of institutional innovation to economic growth}

Institutions regulate the interpersonal mutual relations; institutional innovation can lower the transaction cost and its uncertainty, and improve the allocative efficiency of production factors, then the increasing return to scale would be realized and economic growth would be boosted. From the perspective of functional mechanism, the basic and essential effect of institutional innovation on economic growth is to improve the allocative efficiency of production factors. Therefore, the contribution rate of institutional innovation to economic growth can be calculated through efficiency analysis, the Data Envelopment Analysis (DEA) is just that kind of approach. Through this approach, take the total quantity of labor force, fixed capital stock, human capital stock, as well as science and technique investment as the input, and GDP as the output, the relative efficiency of different DMU (Decision Making Units) could be obtained. The calculation formula of the institutional innovation to economic growth is:

$$
\eta_{I}=i / y=\left(Y_{1} / \theta_{1}-Y_{2} / \theta_{2}\right) /\left(Y_{2}-Y_{1}\right)+1
$$

In Formula (7), $Y_{1}$ and $Y_{2}$ respectively are the total output value of base period and last period, $\theta_{1}$ is the relative efficiency of base period, and $\theta_{2}$ is that of the last period. The relative efficiency of each period, see Figure 1; the calculation result of the institutional innovation to economic growth of each period, see Chart 1.

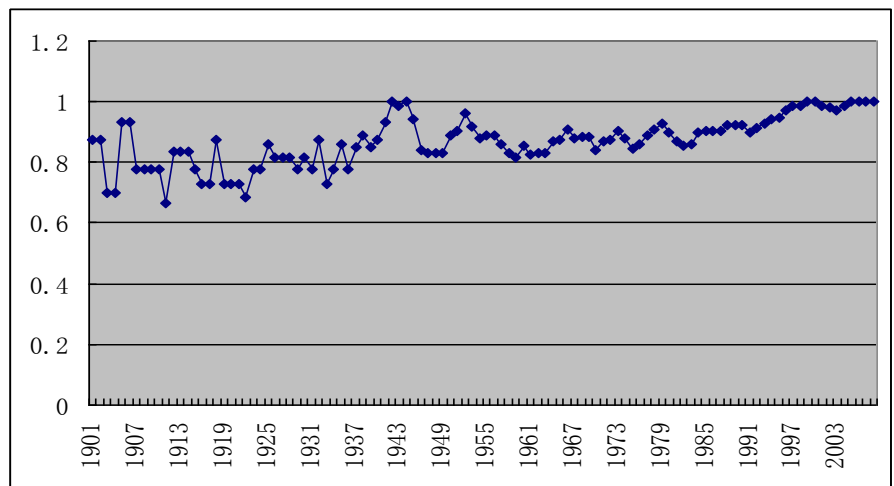

Figure 1 the relative efficiency of production factors allocation between 1900 and 2008 in US

\section{CONCLUSION}

On the basis of symbiosis theory, this paper establishes the growth model for US economy in recent century from 1900 to 2008, and measures the contribution rate of science and technology, human capital, fixed capital stock, investment in fixed assets, system, and the externality of economic environment to US economic growth, and then it analyzes the calculation results, from the perspective of the driving factors of economic growth, they indicate that the United States has been a innovative country since 1982 , for the total amount of 
the contribution rates of its scientific-technical progress, human capital and institutional innovation has surpassed $50 \%$. Human capital and labor force are two important factors for economic growth of US. The sum of the contribution rates of human capital and labor force in each period respectively are $32.9 \%, 26.9 \%, 30.4 \%$, $30.8 \%$ and $23 \%$, which has forcefully promoted the long-term economic growth. Meanwhile, under the environmental conditions of the innovative country, the US economy has stepped into a new stage of sustainable improvement of resource allocation efficiency with lower water consumption and fewer major pollutants.

\section{REFERENCES}

[1]Charles I. Jones. Time series tests of endogenous growth models. Quarterly Journal of Economics, 1995(2): 495-525.

[2]Eicher T. S., Turnovsky S. J. "Non-Scale Models of Economic Growth" The Economic Journal, 1999(109)394415.

[3]D.W.Jorgenson. The Productivity and Economic Growth In Janpan and U.S.. The Journal of Quantitative \& Technical Economics, 1989(4):74-78.

[4]Dale W. Jorgenson, Richard J. Goettle, Mun S. Ho, Daniel T. Slesnick and Peter J. Wilcoxen. U.S. Labor supply and demand in the long run. Journal of Policy Modeling Volume 30, Is sue 4, July-August 2008, Pages 603-618. 